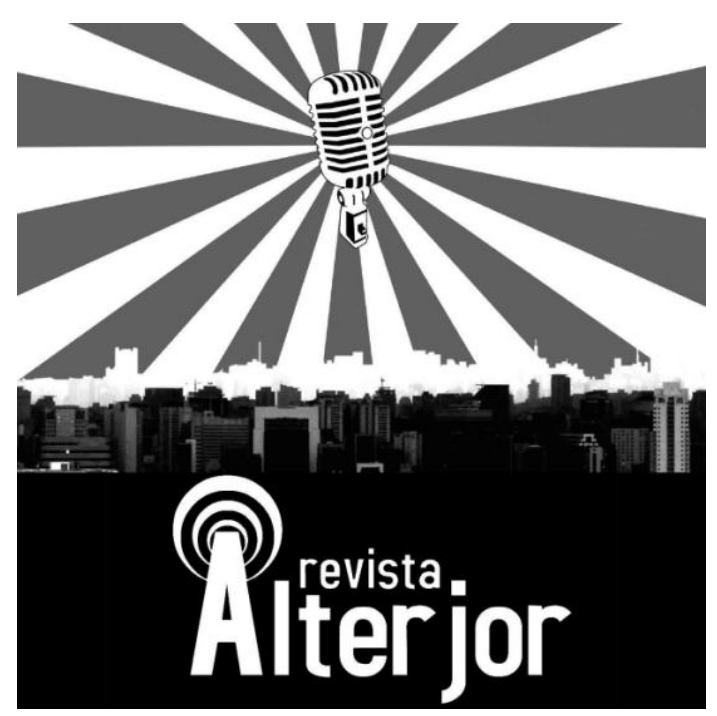

\title{
RÁDIO REGIONAL: UM PATRIMÔNIO CULTURAL IMATERIAL E UM LUGAR DE MEMÓRIA
}

\author{
Elane Gomes Santos Coutinho ${ }^{1}$
}

\begin{abstract}
RESUMO: O rádio faz parte da história e da cultura de diversas regiões do Brasil. Na forma representativa com que se relaciona com estas culturas, o rádio regional, em especial, pode ser considerado como patrimônio cultural imaterial e lugar de memória. Isso vemos acontecer no programa Ranchinho do Jajá, da Rádio Mantiqueira AM 550 de Cruzeiro-SP, objeto deste artigo, que traz como objetivo analisar como os conceitos de patrimônio cultural imaterial e lugar de memória podem ser aplicados ao rádio. Seguindo a abordagem qualitativa, utiliza a estratégia de análise de conteúdo dos comentários de ouvintes do programa. Os resultados mostram que os conceitos de patrimônio cultural e lugar de memória podem ser aplicados ao rádio, a partir do sentido que a recepção dá para o seu conteúdo e seus elementos. A pesquisa contribui, portanto, com os estudos sobre o rádio como patrimônio cultural imaterial.
\end{abstract}

PALAVRAS-CHAVE: Rádio regional. Patrimônio imaterial. lugar de memória. cultura popular.

ABSTRACT: Radio is part of the history and culture of different regions of Brazil. In the representative form in which it relates to these cultures, regional radio, in particular, can be considered as immaterial cultural heritage and a place of memory. This we see happening in the Ranchinho do Jajá program, from Rádio Mantiqueira AM 550, in the city of Cruzeiro-SP, object of this article, which aims to analyze how the concepts of immaterial cultural heritage and place of memory can be applied to radio. Following the qualitative approach, it uses the content analysis strategy of the program's listeners' comments. The results show that the concepts of cultural heritage and place of memory can be applied to the radio, from the sense that the reception gives to its content and its elements. Research, therefore, contributes to studies on radio as an intangible cultural heritage.

KEYWORDS: Regional radio. Intangible heritage. memory place. popular culture.

\footnotetext{
' Graduada em Letras Vernáculas pela Universidade Estadual de Feira de Santana(UEFS),1999; pósgraduada em Meios de Comunicação e Cultura Midiática pela PUC-SP, em 2011; mestranda do Programa de Pós-Graduação Stricto Sensu em Comunicação da Universidade Paulista(UNIP) email: elanecp@gmail.com.
}

Revista ALTERJOR

Grupo de Estudos Alterjor:Jornalismo Popular e Alternativo (ECA-USP)

Ano 10 Volume 02 Edição 22 Julho-Dezembro de 2020

Avenida Professor Lúcio Martins Rodrig̉ues, 443, Cidade Universitária, São Paulo, CEP: 05508-020 


\section{INTRODUÇÃO}

O rádio tem relação intrínseca com a memória nacional e com as memórias de várias regiões e culturas que caracterizam o país. Ele traz em seu bojo um patrimônio de representações simbólicas que ajudam a identificar e interpretar estas culturas.

O modo como o rádio regional se constitui um patrimônio cultural imaterial e um lugar de memória é o tema desta pesquisa, que analisa os conteúdos dos comentários de ouvintes - postados no Youtube - sobre o programa "Ranchinho do Jájá", da Rádio Mantiqueira AM 550 de Cruzeiro - SP.

Muitas emissoras de rádios surgiram no Brasil já na década de 1920, desde a sua inauguração em 1922. Olhando para sua história de quase 100 anos, percebe-se que este meio de comunicação conseguiu se reinventar diante das várias mudanças tecnológicas.

Atualmente, o processo de migração do AM para FM - inaugurado em 7 de novembro de 2013, resultado de questões técnicas e mercadológicas - abriu uma tensão em relação à história e memória do rádio: algumas emissoras de frequência AM regionais, que são aquelas que trazem forte ligação com a cultura popular local e regional, estão mudando a sua forma de produção(estilo, conteúdo, programação, etc.) e, com isso, apagando suas memórias. Outras, no entanto, resolvem permanecer com o mesmo conteúdo, fazendo mudanças parciais. (CURADO, 2015; SANTOS, B.; CAMPOS, D.,2016.; BARRILES et al. 2018). No primeiro processo, quando se faz grandes mudanças, um arsenal de bens simbólicos vai sendo desconstruído, passando a existir no ambiente da memória.

Embora ainda sejam poucas as pesquisas atuais sobre o patrimônio do rádio, algumas delas têm buscado discutir o meio enquanto patrimônio cultural imaterial. De acordo com Adami(em fase de elaboração) ${ }^{2}$, já existe, inclusive, uma preocupação com o registro do rádio com este selo a fim de preservar a história e a memória que ainda há em programas, emissoras e locutores de um modo geral.

\footnotetext{
2 Produção e Memória radiofônica de São Paulo como Patrimônio Cultural, de autoria de Antônio Adami a ser editado pela Revista Documentacion de las Ciencias de la Informacion. Faculdad de Ciencias de la Informacion,UCM, 2020.
} 


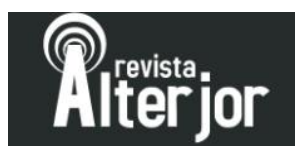

O patrimônio cultural imaterial é aquele que preserva elementos que ajudam a construir as identidades de grupos diversos e interpretar a cultura (FONSECA,2003 67). Essa relação do rádio com a cultura popular e a memória de um povo, e o recente empenho de pesquisadores para que o rádio seja considerado um patrimônio cultural imaterial abre uma discussão pertinente sobre o impacto do fechamento das emissoras AM - as mais antigas operações radiofônicas no Brasil e que mantinham uma relação de proximidade com o seu público. Tais emissoras (ou os registros delas que sobrevivem na plataforma da internet), programas, ou locutores podem ser consideradas hoje o que Nora (2003) define como "lugares de memória", já que, com o fechamento, não há (ou não haverá), meios de memória. Segundo este autor, lugar de memória se constitui no lugar onde a memória reside pela significação simbólica que ele carrega, podendo ser não apenas espaços físicos.

Diante desta reflexão, nota-se que, para se discutir os impactos do processo de migração na história e memória do rádio hoje, bem como na cultura onde ele está inserido, é necessário analisar os aspectos de patrimônio cultural imaterial e lugar de memória presentes neste meio de comunicação. Sendo assim, a questão que se levanta é a seguinte: De que forma o rádio se constitui hoje um patrimônio cultural imaterial e um lugar de memória? A partir dessa problemática, o objetivo proposto neste artigo é discutir como o rádio se configura um patrimônio cultural imaterial e um lugar de memória, considerando os efeitos da migração de rádios AM para FM na salvaguarda da memória da cultura popular, na qual a emissora está inserida. A pesquisa se torna importante para a compreensão da relevância do rádio hoje na representação simbólica e visa contribuir com os estudos sobre o rádio regional, preenchendo as lacunas nas pesquisas do rádio no Brasil enquanto patrimônio cultural imaterial e lugar de memória.

Além dos autores já citados, referência importante neste estudo é a definição a respeito do patrimônio cultural imaterial discutida por Regina Abreu e Carlos Chagas (2003). José Gonçalves (2003), ajuda na reflexão de uma possível caracterização do patrimônio imaterial. Outro trabalho que fundamenta a discussão é o de Márcia Sant'Anna (2003), que explica como o conceito de patrimônio imaterial foi sendo 


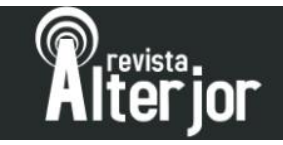

implantado no Brasil. Maria Cecília Fonseca (2003) acrescenta à reflexão sobre a forma como o patrimônio imaterial se relaciona com a identidade cultural.

Quanto à metodologia, a abordagem seguiu o método qualitativo e exploratório já que são poucos os estudos que analisam o rádio usando os conceitos de patrimônio cultural imaterial e lugar de memória. Uma vez que se observou que a memória dos ouvintes dá vida novamente ao programa, optou-se por estudar tais conceitos partindo da audiência, fazendo uma análise de conteúdo dos comentários dos ouvintes sobre um vídeo de homenagem ao locutor e ao programa, postado no Youtube. Foram realizadas pesquisas de internet, pesquisa bibliográfica, observação e análise categorial com base no esquema elaborado por Flores (1994). A proposta foi verificar de que forma os conceitos trabalhados se aplicam ao rádio. Por isso, eles mesmos foram as metacategorias que utilizamos na análise. A categorização teve por base o referencial teórico deste trabalho.

Usando os conceitos de Creswell (2010), as coletas de dados foram obtidas por meio das seguintes fontes:

- Observação participante: Foram feitas observações da rádio e anotações de campo não estruturadas durante visita à emissora. Em seguida foram registrados os dados obtidos a partir dos relatos dos profissionais da Rádio Mantiqueira. Eles serviram de base para discussão proposta.

- Documentos: Foram analisados documentos institucionais da Rádio Mantiqueira AM 550 que ainda estão disponíveis na internet. Foi fotografado o prédio atual da emissora e analisado o Requerimento $\mathrm{N}^{\circ} .2835$, de 2001, publicado no site da Assembleia Legislativa do Estado de São Paulo, após a morte do locutor do programa estudado neste artigo (o Jajá). Este documento traz dados sobre sua carreira. Foi feita também uma análise da edição 59 do jornal regional, $O$ Impacto da Notícia, que faz uma reportagem sobre a história da Rádio Mantiqueira.

- Material audiovisual: Durante dois meses, por três horas semanais, foram realizadas escutas da programação atual da emissora, a fim de conhecer a rádio e sua proposta. Fez-se também exame, coleta e transcrição do material 


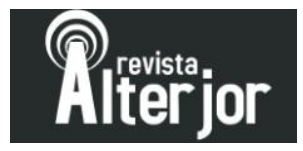

audiovisual postado na internet sobre a rádio, o locutor e o programa. Foi feita ainda a coleta e análise dos 14 comentários do vídeo (de homenagem ao programa) postado no youtibe. Este exame foi o pilar central da coleta de dados. Ele viabilizou as análises das respostas dos ouvintes do programa.

A seguir, apresentamos alguns dados importantes sobre o obejeto a ser analisado.

\subsubsection{RANCHINHO DO JAJÁ NA RÁDIO MANTIQUEIRA AM 550 DE CRUZEIRO-SP}

O Ranchinho do Jajá foi um programa lançado em 1958, na então Rádio Clube de Passa Quatro-MG. Em 1967, o locutor, Jair Batista de Oliveira, Jajá, relançou o programa na Rádio Mantiqueira de Cruzeiro AM 550, quando a rádio pertencia à Fundação Nossa senhora Aparecida. Em 1997, o Ranchinho do Jajá completou 30 anos na emissora paulista, existindo por cerca de 32 anos ininterruptos de programa na emissora de Cruzeiro-SP.

O locutor Jajá iniciou como profissional de rádio na Mantiqueira e, seis meses depois, foi para São Paulo, onde trabalhou em diversas emissoras. Morou 13 anos capital paulista e voltou a Cruzeiro, levando o programa para a Mantiqueira. O locutor chegou a receber uma homenagem da Câmara Municipal da cidade, pelo programa Ranchinho do Jajá, com a entrega de um cartão de prata. ${ }^{3}$ Jair Batista de Oliveira faleceu em 2001 e foi lembrado na Assembleia Legislativa do Estado de São Paulo.

Segundo relatos dos antigos colegas de trabalho (informação verbal) ${ }^{4}$, o Jajá se destacava pela criatividade que usava na produção dos programas e sabia se apropriar da capacidade do rádio de mexer com o imaginário das pessoas. Conta-se que ele ia até uma fazenda, gravava sons de animais e barulhos próprios deste local, para gerar peças sonoras (efeitos) dos programas. A ideia do locutor com isso era valorizar o campo no

\footnotetext{
3 Entrevista do locutor ao repórter Jorge Abreu. Disponível em: https://www.youtube.com/watch?v=LbIIRbksuO8. Acesso em: 01 de novembro de 2019

${ }^{4}$ Noticia fornecida por funcionários da rádio, durante a visita feita à sede da emissora, em Cruzeiro, em outubro de 2019.
} 


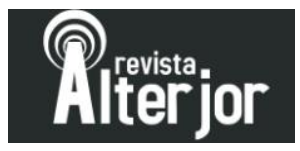

rádio e alimentar a curiosidade das pessoas (informação verbal) ${ }^{5}$. Alguns acreditavam que ele realmente estivesse em um rancho

O locutor, o programa e a rádio exerciam forte influência na região. Segundo o jornal local, O Impacto, Ranchinho do Jajá, era um dos principais programas sertanejos de rádio da cidade (CARVALHO, 2017). Atualmente não foram encontrados nenhum registro sonoro ou impresso do programa. ${ }^{6} \mathrm{O}$ único material encontrado foi um vídeo, postado no youtube em homenagem ao locutor e ao programa, que apresenta 54 segundos do Ranchinho com música de abertura, a voz do locutor saudando os ouvintes, imagens do campo e do Jajá trabalhando no prédio da emissora. O vídeo traz também a voz de um outro locutor homenageando o programa e o Jajá.

O corpus usado na pesquisa foram os 14 comentários de ouvintes do programa em reação a este vídeo. ${ }^{7}$ O critério de escolha deste corpus foi a observação de que, embora o Ranchinho do Jajá não exista mais, está presente na história, na memória e nos momentos significativos dos ouvintes, e nos relatos dos funcionários na emissora. Ele também manteve uma forte relação com a cultura popular local, seja com a representação que fazia desta cultura, seja como apoio aos aristas locais.

A Rádio Mantiqueira é a emissora mais antiga do Vale do Paraíba e a sexta do Brasil, fundada em 1934 por Guilherme Turner. Em 2016, o canal AM foi desligado, ficando apenas a FM 100,7 também pertencente ao grupo mas que surgiu bem depois. Hoje a rádio é mantida pela Fundação Cruzeirense de Jornalismo e Radiodifusão. A história da Rádio Mantiqueira AM faz parte da história da cidade, uma vez que ela foi inaugurada quando Cruzeiro tinha apenas 33 anos. Esta rádio foi escolhida para análise por ser uma emissora AM, de caráter regional que, pelo tempo de existência, estabeleceu uma forte relação com a cultura popular local, e que sofreu grande impacto com a migração para o FM.

\footnotetext{
${ }^{5}$ Notícia fornecida por familiar, através de telefone, em São Paulo, em novembro de 2019 ${ }^{6} \mathrm{~A}$ pesquisa mobilizou a procura por parte de colegas e familiares do locutor, porém nada foi encontrado. 7 O RANCHINHO DO JAJÁ COM JAIR BATISTA(O JAJÁ). Disponível em: https://www.youtube.com/watch?v=pxlia6GwNpE. Acesso em: 01 de outubro de 2019
} 


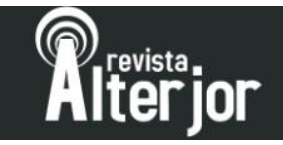

Na próxima seção, abordaremos sobre a aplicação do conceito de patrimônio cultural imaterial no rádio, dando alguns exemplos da Rádio Mantiqueira AM de Cruzeiro-SP.

\section{FUNDAMENTAÇÃO TEÓRICA}

Com as constantes transformações pelas quais passam o rádio, entre elas a migração do AM para o FM, o conceito de lugar de memória e patrimônio cultural imaterial são formas de manter vivos programas, locutores e conteúdos que fizeram a história do rádio e das culturas em diferentes regiões do Brasil e que fazem parte também das memórias destas culturas.

Embora não seja intenção deste artigo, que faz parte de uma pesquisa maior, discutir como tem se dado o processo de migração do AM para o FM no Brasil, vale dizer que ele é fruto tanto das mudanças tecnológicas que foram tornando inviáveis o alcance das emissoras AM - principalmente nos grandes centros - como é também resultado das pressões mercadológicas, uma vez que a mudança é uma antiga reivindicação dos radiodifusores que, com a melhora do áudio, poderão explorar mais a concessão e ter melhores lucros.

Para fundamentar a discussão sobre patrimônio imaterial, partimos das discussões propostas pelas Ciências Sociais, em especial a Antropologia e a História, aplicando algumas características do patrimônio imaterial e do lugar de memória ao rádio, vendo como estas se apresentam na Rádio Mantiqueira, objeto desta pesquisa. Há uma relação entre patrimônio cultural e imaterial e lugar de memória no tocante em que os dois termos dizem respeito a uma realidade simbólica que representa uma cultura e uma memória. Apesar de não ser intenção desta pesquisa, analisar a relação em si destes dois conceitos, nota-se que a noção de lugar de memória proposta por Nora (2003), contribui com a discussão do rádio como patrimônio cultural e imaterial.

\subsection{RÁDIO MANTIQUEIRA AM 550: PATRIMÔNIO CULTURAL}




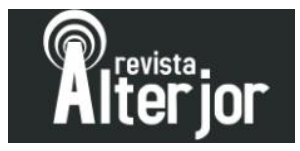

Antes de tratarmos da aplicação do conceito de patrimônio na Rádio Mantiqueira, consideramos relevante pensar no rádio em si enquanto patrimônio cultural e imaterial. Isso nos leva a considerar como ponto de partida qual é a ideia que se considera aqui deste conceito de patrimônio.

Durante muitas décadas o patrimônio era definido a partir de sua dimensão material. O significado de patrimônio estava voltado para a propriedade, a preservação ou para o conceito de herança a ser transmitida. A discussão a respeito não é nova, já que, de acordo com Gonçalves(2003), querer preservar a memória faz parte das sociedades humanas em diversos tempos. A ideia de um patrimônio intangível mudou o paradigma do conceito de patrimônio, fazendo os intelectuais e pesquisadores das ciências sociais voltarem o olhar para as manifestações culturais: "línguas, festas, rituais, danças, lendas, mitos, músicas, saberes, técnicas e fazeres diversificados" (CHAGAS, 2003, p 11).

No Brasil, em 4 de agosto de 2000, foi aprovado um decreto que instituiu o patrimônio cultural imaterial ou intangível. Entretanto, a preocupação com o tema surgiu nos anos de 1930 mas a criação do decreto de tombamento (Dec-Lei 25 de 30 de novembro de 1937) que contemplou apenas o patrimônio material. Uma referência ao patrimônio imaterial foi colocada nos artigos 215 e 216 da Constituição Brasileira de 1988: "Constituem patrimônio cultural brasileiro os bens de natureza material e imaterial, tomados individualmente ou em conjunto, portadores de referência à identidade, à ação, à memória dos diferentes grupos formadores da sociedade brasileira" (BRASIL, 1988). A presença na Constituição leva a entender que a promoção de um patrimônio cultural imaterial é papel de quem lida e interfere de alguma maneira na cultura. Entre estes agentes estão os meios de comunicação de massa, que são um bem público, ainda que a sua maioria, no Brasil, seja dirigida por empresas privadas. A mesma Constituição (BRASIL,1988) no seu Artigo 221, prescreve para os meios de comunicação o fomento da cultura nacional e regional.

Portanto, direcionar uma produção voltada também para as manifestações e representações simbólicas, sejam elas nacionais ou regionais faz parte do papel social 


\section{Rireiorior}

dos veículos de comunicação. E essa gama de produções ajuda a construir o patrimônio cultural imaterial de diversas culturas.

Para se compreender o rádio como patrimônio cultural imaterial é necessário levar em consideração, primeiramente, o que este tema tem a ver com o meio rádio. Algo que é uma tarefa complexa porque os termos "patrimônio", "cultura" e "imaterialidade" têm, cada um, várias acepções. Falando a respeito da palavra patrimônio - que é a categoria sobre a qual estamos tratando nesse momento - na ideia de Gonçalves(2003), ele pode se referir, neste contexto, a um colecionamento de objetos, ou coisas móveis e imóveis, ou a bens que nem sempre são para uso práticos mas que carregam uma significação, ou a um fato social de qualquer natureza (GONÇALVES, 2003 apud MAUSS, 1974). Para Gonçalves (2003, p.23) o patrimônio pode ser também a "extensão do seu proprietário." Trazendo essa ideia para o contexto desta pesquisa, verifica-se que uma rádio regional pode ser considerada a extensão ou parte da cidade ou da região em que está sediada. De acordo com esta ideia, quando uma região reconhece uma emissora como seu patrimônio, ela pode se apropriar do veículo como extensão do seu espaço. É o que veremos adiante sobre o modo como a cidade de Cruzeiro se apropriou da Rádio Mantiqueira

O patrimônio cultural imaterial, traz ao debate "as narrativas urbanas, regionais e locais, nas quais está em jogo a construção de uma identidade específica, capaz de articular outras tantas narrativas"(ABREU; CHAGAS, 2003, p.13). Uma vez que o conceito de patrimônio cultural imaterial traz à tona as representações simbólicas de locais que, até então, não eram considerados, nota-se que isto é também o que faz (ou deveria fazer) as rádios regionais no exercício do seu papel social.

Outra noção trabalhado neste conceito de patrimônio cultural - a imaterialidade pressupõe algo que você não retém, não é tangível, ainda que se refira à culinária, festas, modos de fazer, algo que tocamos através dos sentidos ou da mente. Eles são espontâneos e se transformam com o tempo, por isso a ideia do registro, a fim de marcar a sua presença e seu processo de mudança (GONÇALVES, 2003, p. 27). A imaterialidade em questão está nos sentidos e nas significações que os elementos expressam dentro de uma cultura. Este modo de pensar o patrimônio é, segundo 


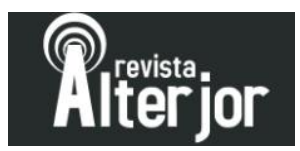

Gonçalves (2003) uma influência da antropologia moderna e seu conceito de cultura, entendida como o conjunto diversificado de representações e realizações materiais ou imateriais de um determinado povo, tomando como base as ideias de Abreu (2003).

O registro dos conteúdos, locutores e linguagens de rádio como patrimônio imaterial da cultura seria também uma maneira de tornar conhecida a produção radiofônica de diversas regiões do Brasil, bem como "o contexto em que ocorreram e o sentido que têm para os diferentes produtores e destinatários" (FONSECA, 2003, p.71). Tais produções nem sempre são lembradas na história oficial do rádio mas constituem formas de expressão que representam identidades e ajudam a compreender, por exemplo, as tradições e os valores das culturas regionais presentes no país. Isso também dá condições para que essas culturas preservem a sua memória e se desenvolvam a partir do conhecimento de suas riquezas simbólicas.

Falando sobre a noção de patrimônio, na Rádio Mantiqueira, verifica-se que este conceito se relaciona com e emissora, tanto no que diz respeito ao patrimônio cultural imaterial, quanto ao patrimônio cultural material ${ }^{8}$. Muitas emissoras foram ou ainda são, um lugar que preserva a história da música brasileira por terem sido o local onde estas músicas circularam e chegaram ao imaginário de tantas pessoas, gerando significações. As rádios, no passado, se tornaram verdadeiros arquivos de uma gama de LPs, reunindo produções que fizeram a história da música, como relata o jornal $O$ Impacto da Notícia sobre o arquivo da Rádio Mantiqueira:

Desde os primeiros discos de vinil lançados no final da década de 1940, a discoteca da Rádio Mantiqueira colecionou perto de $30 \mathrm{mil} \mathrm{em}$ formato LP e compacto. O acervo chegou a ser considerado um dos maiores do País. Havia coleções completas de cantores, de bandas e de orquestras nacionais e internacionais. Pois bem, há cerca de cinco[hoje oito] anos, milhares de LPs e de compactos saíram da Rádio Mantiqueira vendidos por R\$ 1 . Isso sem contar os que simplesmente desapareceram. (CARVALHO, 2017)

A relação da sociedade com a Rádio Mantiqueira AM era tão forte que, em 1984, com a decisão de uma possível venda da Rádio - com a história de que a emissora

\footnotetext{
${ }^{8}$ Pontuamos este aspecto apenas a título de observação, uma vez que o nosso trabalho se detém em estudar o rádio como patrimônio cultural imaterial, não discutiremos a ideia de patrimônio material.
} 


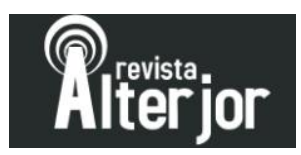

passava por problemas financeiros, correndo o risco ser fechada - criou-se uma campanha entre diversos organismos da sociedade a fim de pressionar a prefeitura a comprar a emissora. Segundo o jornal O Impcto, a história é controversa, pois a Rádio não passava por problemas financeiros.

Em pouco mais de uma semana, foram entrevistados líderes de bairros e presidentes de sindicatos. Como uma orquestra bem ensaiada, todos opinaram que a Prefeitura "deveria salvar a Mantiqueira como patrimônio do povo". Ao final da campanha, o prefeito Paulo Scamilla confirmou a compra, sob o argumento de que a Prefeitura iria equilibrar as finanças da rádio para depois devolvê-la à iniciativa privada. (CARVALHO, 2017)

Independentemente da veracidade sobre a questão financeira, relatos de alguns membros da Rádio Mantiqueira narram que, de fato, houve uma pressão da sociedade para que a prefeitura comprasse a Rádio, a fim de que ela não desaparecesse. De fato, a compra foi feita. ${ }^{9}$ O que nos interessa nesta história é perceber que, realmente, a sociedade local tem envolvimento com a Rádio e a considera um patrimônio, parte da sua própria história, havendo assim um interesse público de salvaguardá-la. Este reconhecimento da sociedade caracteriza um patrimônio imaterial.

Em 1985 foi criada então pela prefeitura a Fundação Cruzeirense de Jornalismo e Radiodifusão e colocados conselheiros de governo municipal para direção da emissora. A rádio se torna desta forma, teoricamente, a um patrimônio público. A emissora foi aqui, de acordo com Gonçalves (2003, p.27) uma a "extensão" da cidade que se apropriou dela para salvar sua memória.

Ainda segundo o jornal, após a saída do prefeito do governo municipal, a rádio fica na mão de assessores. Perde anunciantes e vive um período de decadência: altos custos, ações trabalhistas entre outras coisas. O pátio de transmissão é leiloado e os equipamentos da rádio sucateados, levando a emissora AM a sair do ar no final do ano de 2016, ficando apenas o canal FM. O momento de decadência coincidiu com o período das migrações no Brasil das rádios AM para a FM e foi um dos motivos do fechamento da rádio.

\footnotetext{
${ }^{9}$ Noticia fornecida por funcionários da rádio, durante a visita feita à sede da emissora, em Cruzeiro, em outubro de 2019.
}

Revista AL TERJOR

Grupo de Estudos Alterjor:Jornalismo Popular e Alternativo (ECA-USP)

Ano 10 Volume 02 Edição $22 \quad$ Julho- Dezembro de 2020

Avenida Professor Lúcio Martins Rodrig̉ues, 443, Cidade Universitária, São Paulo, CEP: 05508-020 


\subsection{RÁDIO MANTIQUEIRA AM 550: LUGAR DE MEMÓRIA}

Com as constantes transformações pelas quais passam o rádio, entre elas, a migração do AM para o FM, a ideia de lugar de memória é uma das formas de manter vivos tantos programas, locutores e conteúdos que fizeram a história do rádio e das culturas em diferentes regiões do Brasil. Tais elementos ainda estão na memória de vários grupos. Embora muitas rádios tenham optado por migrar e manter os mesmos formatos e programas, algumas emissoras, que sobreviveram por décadas, estão se fechando, afiliando-se às redes ou mantendo apenas as frequências de FMs, que já existiam com uma programação diferente, como foi o caso da Rádio Mantiqueira AM 550 de Cruzeiro-SP. Isso tem levado à perda de um grande acervo de programas, conteúdos e locutores que fazem parte da história e da memória das culturas regionais das quais estas rádios fizeram parte. Essa perda tem impacto direto na representação e no conhecimento da cultura destes povos.

Nesse momento da história do rádio, encontrar "lugares onde a memória se cristaliza e se refugia" (NORA, 2012, p.7) faz-se necessário uma vez que a migração não leva a uma descontinuidade da história das pessoas e da região que conviveu com a emissora ou, ao menos, não deveria levar.

A partir o fechamento da emissora AM 550, em 2016, restou apenas a Rádio FM 100.7 que traz somente dois programas da antiga $\mathrm{AM}^{10}$. A FM já existia antes do fechamento por isso possuía uma programação própria. A rádio AM, que existiu por mais de 80 anos, trazia uma história com a região e com o público, possuía uma relação com a cidade a partir dos seus programas e dos locutores. A emissora se foi com todo o seu acervo de LPs e programas que poderiam contar a história da rádio e suas produções que, ao longo de décadas, faziam parte da vida de seu público. A rádio, que foi a primeira emissora da região do Vale do Paraíba e a sexta do Brasil, hoje, não existe fisicamente, levou com ela uma parte da história da cidade e das pessoas, mas está presente na memória de quem a ouviu.

\footnotetext{
${ }^{10}$ Informação fornecida por funcionários da rádio, durante a visita feita à sede da emissora, em Cruzeiro, em outubro de 2019.
} 


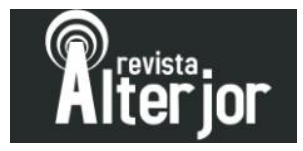

De acordo com Pierre Nora (2012, p.13), “os lugares de memória nascem e vivem do sentimento que não há memória espontânea, que é preciso criar arquivos.” Os registros das rádios que estão se desligando ou se transformando com este processo de migração, serve como lugar possível de se recuperar a memória do grupo, da região e do rádio em si.

O programa Ranchinho do Jajá, escolhido como objeto desta pesquisa, é um dos exemplos de programa que só existe na memória dos ouvintes, como "restos" que subsistem (NORA, 2012 p. 12). Não há na emissora nenhuma cópia gravada deste programa. Para pesquisa, foi feita uma busca na própria rádio e através de contatos com profissionais contemporâneos do locutor e com familiares, porém, não foi encontrado, até o momento, nenhum registro do programa, além do vídeo no youtube, postado em 2008, com 54 segundos do Ranchinho do Jajá. ${ }^{11}$

A memória dos mais de 30 anos do programa, na Rádio Mantiqueira AM 550 é contada pelos comentários de seus ouvintes como veremos mais adiante. Neste caso, ainda que o conceito de lugar de memória não se refira estritamente a algo físico, os poucos segundos de programa serviram de lugar de memória porque foram postados justamente para lembrar; existe ali uma "vontade de memória", já que não há mais memória (NORA, 2012).

A Rádio Mantiqueira AM trazia uma forte ligação com a memória do grupo em seu contexto social e político. Como informa também o jornal O Impacto da Notícia, ainda na década de 1950, a emissora teve forte assédio político notadamente durante os debates. "A transmissão das apurações das eleições exigia fôlego dos repórteres. Na cidade, ninguém desgrudava do rádio até o encerramento da reportagem." (CARVALHO, 2017)

O resgate da história da emissora deve trazer à tona a memória do que acontecia na cidade. Aqui, a história vira memória (NORA, 2012). A cidade de Cruzeiro sempre foi marcada pela efervescência da vida cultural, desde a criação da linha de trem - que acabou fomentando o surgimento de cinemas, cabarés, teatros entre outros elementos de representação cultural - e a Rádio Mantiqueira também fez parte deste processo.

\footnotetext{
${ }^{11}$ Informação fornecida por funcionários da rádio, durante a visita feita à sede da emissora, em Cruzeiro, em outubro de 2019.
} 
A partir de 1938, com o lançamento de programas de auditório e de rádio novela, a Mantiqueira fomentou a cultura local proporcionando o surgimento ou o fortalecimento de grupos de teatro e de canto. (CARVALHO, 2017)

A apesar de ter sido desligada, a Rádio Mantiqueira AM está presente na memória dos ouvintes e profissionais, e os raros registros achados na internet são modos de mantê-la viva como patrimônio cultural imaterial da cidade e como lugar de memória para a sociedade e para cada ouvinte. Embora não haja registro, só o nome da Rádio, do programa ou do locutor já faz dela um lugar de memória neste tempo. Na próxima sessão, será apresentada uma análise dos comentários dos ouvintes que mostra como a rádio, o programa e o locutor se tornaram, para eles, um patrimônio cultural imaterial e também um lugar de memória.

\section{APRESENTAÇÃO, ANÁLISE E INTERPRETAÇÃO DE RESULTADOS}

Os 14 comentários publicados pelos ouvintes na plataforma Youtube sobre o vídeo intitulado "O Ranchinho do Jajá com Jair Batista(o Jajá)" - uma homenagem ao locutor e ao programa Ranchinho do Jajá, pelos seus 30 anos no ar - foram coletados, impressos e analisadas. Como a ideia é analisar a recepção, optou-se em trabalhar com os próprios escritos dos ouvintes, sua linguagem e uso de palavras.

Para análise do conteúdo das respostas dos ouvintes, os dados gerados pelos documentos estudados foram reduzidos e condensados em metacategorias. Conforme mencionado anteriormente, esta proposta de análise foi inspirada na análise categorial de Flores (1994). As etapas de análise dos documentos foram as seguintes:

1. Inicialmente foram criadas duas grandes categorias, que partiram do problema de pesquisa e da teoria, são elas: patrimônio cultural imaterial e lugar de memória. De acordo com Adami(2019), a noção de patrimônio cultural imaterial, no rádio está na produção em si, desta forma optou-se por analisar estas categorias a partir de elementos da produção radiofônica, subcatecorizando assim as metacategorias da seguinte forma: 
a) Patrimônio cultural imaterial: Locutor, programa, emissora

b) Lugar de memória: locutor, programa, emissora

2. Em seguida, reduziram-se os dados dos comentários dos ouvintes por componentes temáticos que foram agrupados a cada uma destas metacategorias e subcategorias, a partir da identificação dos assuntos das postagens com os conceitos encerrados nos temas centrais (metacategorias). Os dados foram segmentados e agrupados da seguinte forma:

1. Patrimônio cultural imaterial:

a)Locutor: figura próxima e inspiradora, significativo na vida dos ouvintes, fomenta cultura regional;

b)Programa: Traz elementos da cultura, identificação do público, faz parte da rotina do público;

c)Emissora: Espaço de valorização cultural.

2. Lugar de memória:

a)Locutor: imortalizado na memória;

b)Programa: torna presente o passado, confere valor ao passado;

c)Emissora: ativa memórias de experiências vividas.

Ao agruparmos os dados em categorias, foi possível perceber como os conceitos de patrimônio imaterial e lugar de memória se aplicam ao rádio, isso possibilitou também estabelecer relações entre estes dois aspectos. Verificou-se ainda que há uma interdependência entre metacategorias e subcategorias. Entretanto, com a segmentação temática, pode-se fazer uma análise mais detalhada da aplicação dos conceitos ao rádio, verificando a partir das significações dos ouvintes o que foi discutido na teoria. A análise da audiência do rádio foi fundamental para entendimento dos conceitos. A seguir, apresentamos a análise das metacategorias.

\subsection{PATRIMÔNIO CULTURAL IMATERIAL}

Os ouvintes veem o programa Ranchinho do Jajá como um bem, que lhe serviu e fez parte de sua vida. Ele é a representação de sua cultura. Desta forma, sentem 


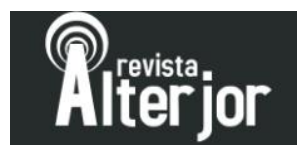

profunda identificação com o produto da emissora. Isto fica evidenciado nas subcategorias de interação. A análise mostra que tanto Jajá, quanto o programa e a emissora fazem uma mediação entre os ouvintes e a sua própria cultura, algo que é próprio do patrimônio cultura imaterial, conforme afirma Gonçalves (2003).

De acordo com Adami (2019), no que se refere ao rádio, podem ser considerados patrimônio cultural imaterial a emissora, os programas e locutores, além de vários outros elementos envolvidos na produção. Nesta pesquisa, a análise do corpus permite trabalhar com estes três elementos mencionados pelos ouvinte nas postagens: locutor, programa e emissora.

\section{a)Locutor:}

- Figura próxima e inspiradora: O Jajá é visto pelos ouvintes menos que um locutor ou um personagem e mais como figura próxima e inspiradora: "Ouvindo jajá em minha infância, foi que me surgiu inspiração pra ser locutor de rádio, aprendi muito com ele..."(Biby).

- Papel significativo na vida dos ouvintes: Os ouvintes relatam a importância dele em suas vidas.

"homenagem muito legal mais do que justa esse homem, um dos maiores radialistas na parte da manhãzinha não tinha igual eu quero deixar aqui o meu abraço no coração de toda família de Jair Batista, o Jajá pois foi ele que lançou para todo o brasil a dupla Ednaldo e Adriano estamos aqui eu Adriano e o meu amigo Ednaldo. Deixamos aqui nosso carinho e respeito Jajá você faz parte de nossa história Ednaldo e Adriano.

- Fomenta a cultura regional: A audiência reconhece também o papel do locutor na propagação da cultura regional. O fato evidencia o que Gonçalves(2003) destaca como papel do patrimônio como mediador entre o ouvinte e sua cultura, sobre o qual já nos referimos anteriormente:” Amante das raízes, da sua Passa Quatro e de Cruzeiro” (Antônio Carlos); “... foi alí que ganhei o dom da comunicação, com esse grande mestre da comunicação regional”. 


\section{b) Programa:}

- Traz elementos da cultura: Os ouvintes encontram no programa músicas e artistas que representam sua cultura, e isso credita (ao programa) a reponsabilidade com a cultura.

Anos entre 60 a 70, aos domingos, íamos também aos estúdios da radio mantiqueira assistir as duplas regionais da época, tais como Lopes e Tiãosinho, trio rouxinol, toninho e zé moreno, chiquinha e mariquinha, laurindo e lauriano e tantos outros..Eu achava bonito e ficava fascinado com tudo aquilo[sic].(BiBy)

Percebe-se também nesta fala do ouvinte que o programa colecionava uma série de símbolos culturais. Tal papel caracteriza o patrimônio imaterial (GONÇALVES, 2003).

- Identificação e aceitação do público: Os ouvintes mencionam a grande audiência que tinha o programa, tamanha era a aceitação do público:

“... ia para escola,[e em] todas as casas a gente escutava o programa do Jájá que saudades ia para as fazenda tomar leite tirado na hora, que escutava lá o programa do Jajá .... saudades eterna [sic] do nosso amigão Jajá r família”. (Elvira)

- Faz parte da rotina do público: Também neste mesmo comentário, nota-se, pela ênfase dada nas palavras da ouvinte, que o público se apropriava do programa como parte da sua rotina, tal qual uma extensão dos seus afazeres. Essa apropriação e extensão, são próprios também da noção de patrimônio cultural imaterial, apontada por Gonçalves (2003).

\section{c) Emissora:}

- Espaço de valorização cultural: A emissora aparece aqui intensamente ligada ao locutor. Os ouvintes lembram da rádio e do programa como espaço de 


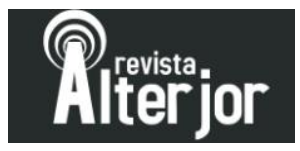

valorização cultural, devido à divulgação de artistas regionais. "Sou a cantora Tropeirinha do rancho, cantei por alguns anos na rádio Mantiqueira aos domingos e também fazia shows com a Caravana do Jajá...Tempo bom." (Maria da Silva). O comentário acima também mostra que os ouvintes se manifestam sobre a emissora, revelando o papel que a rádio exerceu em suas vidas.

O fato evidencia que a rádio, através do programa, por diversas questões, inclusive as mercadológicas, buscava trazer ao centro os temas e expressões regionais. Aqui o caráter do rádio regional se identifica com o conceito de patrimônio cultural imaterial, no tocante em que este busca trazer ao debate formas de expressões locais muitas vezes desconsideradas.

\subsection{LUGAR DE MEMÓRIA}

Nesta metacategoria é possível conceber o trecho do programa apresentado no vídeo postado no youtube como um lugar de memória, e o que leva a esta concepção são justamente os 14 comentários dos ouvintes sobre a postagem. Eles trazem à lembrança memórias do que os ouvintes viviam durante o tempo em que o programa estava no ar, além de memórias sobre o programa em si. Percebe-se que, neste mesmo produto, encontram-se mais de um lugar de memória: locutor, programa e emissora. Cada um, se constitui em um lugar em que a significação que lhes é dada exerce o papel de "parar o tempo, bloquear o trabalho do esquecimento... e prender o máximo de sentido num mínimo de sinais" (NORA, 1993, p. 22). De fato, como já mencionamos, menos de um minuto de programa foi o suficiente para ativar uma série de significações. Além disso, a ideia de se fazer uma homenagem ao programa expressa uma "vontade de memória", ou seja, uma intenção de que locutor, programa e emissora sejam lembrados.

\section{a) Locutor:}

- Imortalizado na memória: De acordo com Nora (1993, p, 22), o lugar de memória tem, além de outras coisas, o papel de "imortalizar a morte", e isso 


\section{Ritieior}

aparece nos comentários dos ouvintes. Apesar de o vídeo ter sido postado há sete anos e o locutor ter falecido há dezoito, ele é tratado, em alguma medida, como se ainda estivesse vivo. Fala-se com o locutor, como se este pudesse interagir ou usa-se o verbo no tempo presente, mostrando esta ideia de imortalidade : "...que saudade Jájá, onde vc estiver esteja em Paz.” (Caprichoso) e “...Jajá você faz parte de nossa história.”(Ednaldo e Adriano)

Além disso, o vídeo traz à memória dos ouvintes as ideias e as atitudes do locutor, fazendo um "bloqueio no esquecimento", de sua pessoa neste momento. (NORA, 1993, p.22).

"Pra encerrar lhe diria: foi ali que ganhei o dom da comunicação, com esse grande mestre da comunicação regional..."(Bibi);

“... ele era amigo do meu pai, e por ser uma pessoa especial junto com sua família, só aumenta a nostalgia de relembrar minha infância..."(Betânia);

"Amante das raizes, da sua Passa Quatro e de Cruzeiro. Saudoso Jajá....que adorava nossa também saudosa "Maria Fumaça". (Antônio Carlos);

"...homenagem muito legal mais do que justa [a] esse homem um dos maiores radialistas na parte da manhãzinha não tinha igual. "[sic](Adriano)

Os comentários acima evidenciam que é possível traçar um pequeno do perfil do locutor. Neste sentido, este lugar de memória, "fixa um estado" da personalidade do Jajá, reconstruindo-a. Isso para Nora (1993) é papel do lugar de memória.

\section{b) Programa:}

- Torna presente o passado: O programa se constitui um lugar de memória no tocante em que ele aciona as memórias dos ouvintes, remetendo-lhes a fatos do passado que, neste momento, se tornam presentes: "que saudade fez parte minha infância, o tempo bom[sic]." Liliane). Alguns lembram de uma rotina de vida ligada à escuta do programa. De acordo com Nora (2012,p.22), “o lugar de 


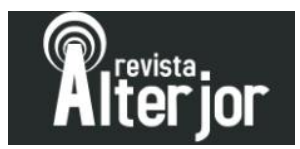

memória se constitui de um jogo da memória e da história”. O programa está envolvido com a história dos ouvintes:

"lembro de 1992... eu levantava pra ir pra escola e minha mãe ligava no programa dele [sic]” (Rodrigo);

"Saudade ...eu também levantava cedo e lá na cozinha minha mãe já ouvia esse saudoso Jajá. voltei ao passado que bom!!!" (Jane);

"Que saudade da minha infância na casa da minha avó acordava com o programa do Jajá era tão bom a gente era feliz e não sabia..." (Elvira Fonseca).

- Confere valor ao passado: Além deste lugar de memória tornar presentes os acontecimentos passados, estes comentários mostram que os ouvintes conferiram valores e significações a este passado evocado. $\mathrm{O}$ uso de expressões valorativas evidencia isso: "que bom", "era tão bom”.

\section{c) Emissora:}

- Ativa memórias de experiências vividas: A rádio é concebida pelos ouvintes como lugar de memória, porque ela em si se relaciona também com fatos de suas vidas. "Sou a cantora Tropeirinha do rancho, cantei por alguns anos na rádio Mantiqueira aos domingos e também fazia shows com a Caravana do Jajá...Tempo bom”( Maria da Silva).

A emissora, como lugar de memória também aciona a lembrança de elementos que são significativos para os ouvintes como, por exemplo, artistas de que gostavam.

"Anos entre 60 a 70 aos domingos íamos também aos estúdios da radio mantiqueira assistir as duplas regionais da época, tais como Lopes e Tiãosinho, trio rouxinol, toninho e zé moreno, chiquinha e mariquinha, laurindo e lauriano e tantos outros..Eu achava bonito e ficava fascinado com tudo aquilo(sic)” (BiBy).

- Relaciona fases da vida: A rádio exerce uma ligação de fases da vida dos ouvintes: 
"Quando criança acordava de madrugada com o "Ranchinho" e depois de adulto tive o privilégio de participar do programa do nosso Jajá contando causos ferroviários (no programa noturno).” (Antônio Carlos).

O ouvinte vai além da lembrança do programa Ranchinho do Jajá que fez parte da sua infância. Sua memória é ativada para lembrar acontecimento também da vida adulta, com outro programa do locutor na emissora. Como lugar de memória, a emissora também reconstitui uma experiência vivida. (NORA, 1993, p.22).

Essa antiga Rádio Mantiqueira AM 550 de Cruzeiro já não está mais no ar, porém, é presente e viva na memória dos ouvintes. Tanto o patrimônio cultural imaterial quanto o lugar de memória, para existirem, precisam estar envoltos de uma simbologia. E as significações que lhe são conferidas, os sentidos e as representações, que ambos abarcam, fazem do rádio um patrimônio cultural imaterial e um lugar de memória. As mesmas interações mostraram estes dois elementos estão presentes no rádio, embora a presença de um não implique, necessariamente, a presença do outro, ou seja, o fato de poderem ser um patrimônio cultural imaterial, não quer dizer que os elementos do rádio serão sempre também um lugar de memória, já que estes, além da significação, necessitam de uma vontade de memória. O que se vê no entanto é que a noção de lugar de memória no rádio ajuda a entendê-lo também como patrimônio cultural imaterial.

Na próxima sessão, apresentaremos as considerações finais desta trajetória de estudos.

\section{CONSIDERAÇÕES FINAIS}

A partir da problemática proposta nesta pesquisa - de que forma o rádio se constitui hoje um patrimônio cultural imaterial e um lugar de memória - o objetivo foi discutir como o rádio se configura nestes dois conceitos, considerando os efeitos das transformações pelas quais o meio passa, atualmente, entre elas: a migração de rádios AM para FM, a morte de seus profissionais ou o desligamento das emissoras por questões mercadológicas. 


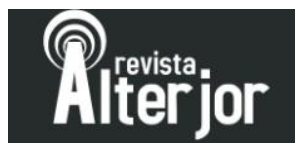

Ao analisar a recepção, foi possível identificar que o rádio como patrimônio cultural imaterial e lugar de memória pode ser entendido a partir da forma como o público que se relaciona com ele e lhe confere significações.

A pesquisa revelou que a noção de patrimônio cultural imaterial se relaciona com o rádio regional, que foi o nosso foco, no tocante em que ambos se voltam para as representações simbólicas de um grupo ou um local específico, representações estas que, muitas vezes, ficam esquecidas no cenário nacional (ABREU;CHAGAS, 2003). Deste modo, conclui-se que registrar emissoras, conteúdos, locutores e outros elementos de produção do rádio como patrimônio imaterial de culturas presentes no Brasil é uma maneira de preservar aspectos que ajudam a construir estas identidades e interpretar as culturas, como discute Fonseca (2003).

No que diz respeito ao lugar de memória, de acordo com as ideias de Nora (2012), nota-se que, ao estabelecer proximidade com o público, o rádio se integra na sua história, nos acontecimentos de suas vidas bem como nas experiências que os ouvintes carregam em si e nas significações que conferem a elas. O rádio pode ser um lugar de memória quando a sua lembrança tem o objetivo de tornar presente estes símbolos e representações, como foi possível notar no estudo sobre a Rádio Mantiqueira AM, que sobreviveu por décadas no Brasil. Constatou-se que o trecho do programa, postado na plataforma do Youtube, ativou um processo de memória que deu vida tanto à emissora, quanto ao programa e ao locutor. Além disso, uniu ouvintes que, se no passado compartilhavam o mesmo espaço regional, hoje, se encontram em outras espacialidades porém unidos nestes lugares de memória descobertos na pesquisa: locutor, emissora e programa. Conclui-se ainda que tomar o rádio como lugar de memória é uma maneira de mantê-lo vivo, também na história já que, como afirma Nora (2012, p.13), “constróise um lugar de memória justamente para que ela não se perca”. E esta memória vivida no rádio não é somente a da rádio em si mas da cultura e dos grupos que ela representa.

A pesquisa foi limitada pelo fato de não haver nenhum registro sonoro ou impresso do programa completo e o fato de não ter sido possível entrevistas com locutores contemporâneos do Jajá, e nem com o diretor da Rádio Mantiqueira FM, 


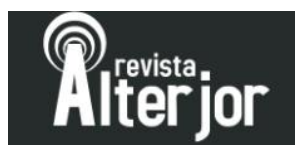

pessoas que poderiam fornecer mais informações sobre a emissora $\mathrm{AM}^{12}$. Estas informações serão relevantes para ampliar este estudo.

Os resultados obtidos servem para fomentar os debates sobre o rádio e trazer elementos teóricos e empíricos sobre o rádio como patrimônio cultural imaterial e lugar de memória, discussões relevantes nesta época de mudanças deste meio no Brasil. Outro ponto que não podemos deixar de apresentar é que o ambiente da web fez o Ranchinho do Jajá ser parte desta pesquisa. Percebemos com isso como a convergência de mídia pode contribuir com a memória e a constituição do patrimônio no rádio. Esta é, inclusive, uma abordagem possível para outros estudos.

\section{REFERÊNCIAS}

ADAMI, Antônio. Produção e Memória radiofônica de São Paulo como Patrimônio Cultural Imaterial. Revista Documentacion de las Ciencias de la Informacion. Faculdad de Ciencias de la Informacion,UCM. No prelo

ABREU, R; CHAGAS, M. (orgs.). Memória e patrimônio: ensaios contemporâneos. Rio de Janeiro, DP\&A, 2003.p.11-14

BRASIL. [Constituição (1988)]. Constituição da República Federativa do Brasil de 1988. Brasília, DF: Presidência da República, [2019]. Disponível em: www.senado.gov.br. Acesso: 14 de novembro de 2019.

CARVALHO, Paulo A. Rádio Mantiqueira, a grande história: depois de mais de 80 anos a AM está fora do ar. O Impacto da Notícia, Cruzeiro, ano 3, n.59, 07 jan. 2017. O Impacto-História, p.7. Disponível em:

http://www.oimpactocruzeiro.com.br/portal/images/impresso/impacto_59_completo.pdf Acesso em: 10 de novembro de 2019

FONSECA, Maria Cecília L. Para além da Pedra e cal. In: ABREU, R; CHAGAS, M. (orgs.). Memória e patrimônio: ensaios contemporâneos. Rio de Janeiro. DP\&A, 2003.p.56-76

GONÇALVES, José R. Os Museus e a cidade. In: ABREU, R; CHAGAS, Mário (orgs.). Memória e patrimônio: ensaios contemporâneos. Rio de Janeiro. DP\&A, 2003.p.21-39

JORNAL O IMPACTO CRUZEIRO. Disponível em: http://www.oimpactocruzeiro.com.br/portal/images/impresso/impacto_59_completo.pdf Acesso em: 10 de novembro de 201

\footnotetext{
${ }^{12}$ Foram contactados, porém não obtivemos retorno.
} 


\section{Areitior}

SANT'ANNA, Márcia. A face imaterial do patrimônio: os novos instrumentos de reconhecimento e valorização. In: ABREU, R; CHAGAS, Mário (orgs.). Memória e patrimônio: ensaios contemporâneos. Rio de Janeiro. DP\&A, 2003.p.46-55

NORA, Pierre. Entre Memória e história: A problemática dos lugares. Projeto História : Revista do Programa de Estudos Pós-Graduados de História, [S.1.], v. 10, out. 2012. ISSN 2176-2767. Disponível em: https://revistas.pucsp.br/revph/article/view/12101>. 